\title{
El arco de San Isidoro de Oviedo. La destrucción del patrimonio monumental ovetense en el primer tercio del siglo Xx. Parte I
}

\author{
Ana María Herrero Montero \\ Archivo Municipal de Oviedo
}

\section{RESUMEN}

El 10 de septiembre de 1925, el Ayuntamiento de Oviedo aprueba la instalación en el Campo de San Francisco del arco de la portada de San Isidoro, último vestigio de aquella iglesia románica. Este artículo, en un viaje a través del tiempo, pretende dar explicación de cómo se llegó a esta situación basándose en los documentos que sobre esta cuestión obran en los distintos archivos ovetenses, a la vez que se presentan otras discutidas actuaciones en materia de destrucción del Patrimonio monumental ovetense en los comienzos del s. XX.

\section{PALABRAS CLAVE:}

Oviedo. Historia. San Isidoro El Real. Patrimonio monumental. Urbanismo (Oviedo).

\section{ABSTRACT}

On the $10^{\text {th }}$ of September, 1925, the Oviedo City Council authorized the installation of the last remains of the Romanesque Church of San Isidoro, its arched portal, in the Campo de San Francisco. On a journey through time, this article aims to explain how this situation arose, with the help of documents from the Oviedo archives, while, in a second part, outlining other controversial acts of destruction of Oviedo's monumental heritage at the beginning of the $\mathrm{XX}^{\text {th }}$ century.

\section{KEY WORDS:}

Oviedo. History. San Isidoro el Real. Monumental heritage. Urban planning (Oviedo). 


\section{Historia de la parroquia}

El 10 de septiembre de 1925, la Comisión Permanente del Ayuntamiento de Oviedo aprueba la instalación en el Campo de San Francisco del arco de la portada de San Isidoro el Real, último vestigio de aquella iglesia románica. Para conocer cómo se llegó a esta situación, objeto de este artículo, habrá que remontarse en el tiempo.

Se desconoce la fecha en que fue consagrado un templo bajo la advocación de San Isidoro en Oviedo, tampoco se encuentran datos sobre la fecha de construcción de la primitiva iglesia románica. No obstante, la documentación de los siglos XIII a XIV, nos lleva a considerar que San Isidoro fue la tercera parroquia establecida en la ciudad, tras San Tirso y San Juan, y seguida de Santa María de la Corte, parroquia filial de la de San Isidoro hasta que el obispo Sanz y Forés la erigió en parroquia independiente el 1 de febrero de 1879.

El primer documento del que tenemos constancia es un pergamino de 1217, de 24 de junio, por el que María Peláiz y su marido, Gonsalvo Petriz, venden a doña María Petriz, a Roderico Dominici y a su mujer María Vermúdiz una casa en El Carpio, feligresía de San Isidoro, por 53 morabetinos ${ }^{1}$.

Tras esta primera mención a San Isidoro como parroquia, en 1237 localizamos una primera referencia a la propia iglesia: el 5 de octubre de 1237 Martín Pico junto con su mujer Aldonza y sus cuatro hijos venden al Maestreescuela Gonzalo Petriz y a su mujer María Sánchiz unas casas en el barrio de San Isidoro por el precio de 160 maravedíes. Dichas casas se encuentran "in fronte rua que vadit ad ecclesia Sancti Isidori"2.

Posteriormente, con fecha 24 de julio de 1240, aparece la primera mención a la calle de San Isidoro en la venta por doña Benayta y sus hijos, Pedro Boniellas y María Domínguiz, a Gonzalvo Petriz y su mujer Marina Guillélmiz de una casa que está en "la rua de San Isidoro". 3

La iglesia se asentaba en el actual solar central de lo que ahora se conoce como Plaza del Paraguas, entre las calles de San Isidoro y Ecce Homo, junto a las murallas.

Las continuas menciones a la cerca y al muro de San Isidoro, antes de la construcción de las murallas de la ciudad, avalan la hipótesis de que la iglesia, como era frecuente en la época, contara con un pequeño murete delimitando sus terrenos.

Archivo Histórico Nacional: carp. 1596, n. 10.

2 Archivo del Monasterio de San Pelayo de Oviedo: leg. C, n. 75

3 Archivo de la Catedral de Oviedo (en adelante, ACO): Serie $A$, carp. 6 , n. 16
El hallazgo, en las excavaciones arqueológicas realizadas en esa zona, de varios paños intramuros al cercado medieval que, según la arqueóloga Gema Adán, no parecen tener carácter defensivo, respalda esta hipótesis ${ }^{4}$. Podemos ver menciones a este murete en la venta de una casa, en enero de 1253, por parte de Johan Estévaniz a Johan Martínez y a su mujer María Martín "so la cerca de Santo Isidoro" 5 , y en la designación de límites para construir el muro de la cerca de Oviedo que hizo Pérez Daor el 13 de febrero de 1270, autorizado por la Real Provisión que se inserta, expedida en Logroño por el rey Don Alfonso X a 20 de enero de 1270: "et de los ommes bonos de la villa digo et mando de parte de nuestro señor el Rey que el muro de la cerca vaya por estos logares que comiencen por el muro de Sante Isidro et en essa plaza de la vinna fagan una puerta por que poda entrar Carro cargado"6.

Por último, la primera referencia como plaza se remonta al 10 de octubre de 1314 Pedro Peliz vende al deán Martín López la mitad de una casa en La Viña, dentro de la cerca, junto a la "plaça de la dicha iglesia de Santo Isidro"7.

La importancia de San Isidoro como templo parroquial viene dada por dos hechos fundamentales: en primer lugar, era la parroquia en la que se enclavaban las Casas Consistoriales y, en segundo lugar, era la parroquia de lo que vendría a ser el centro mercantil de la ciudad y, por tanto, centro de actividad y crecimiento económico y social.

Como parroquia del Consistorio, en ella tenían lugar aquellas celebraciones de carácter oficial que no necesitaran de la ostentación y grandeza de las ceremonias que se llevan a cabo en la Catedral, como fueron las rogativas por la salud de Isabel de Portugal, esposa de Carlos V, el 20 de Julio de 1533, celebradas en San Isidoro: "Misa y sermón, rogando á Nuestro Señor por la vida y salud, de la Emperatriz, y se pregone para que los vecinos de la Ciudad y arrabales, con los mozos y mozas mayores de diez años, concurrieran con candelas"8.

4 GEMA ADÁN ÁLVAREZ, "La muralla de Oviedo: construcción, arreglos y desarreglos», en Actas del Primer Congreso $\mathrm{Na}$ cional de Historia de la Construcción, Madrid, 19-21 septiembre 1996, I. Juan de Herrera, CEHOPU, Madrid, 1996, pp. 5-12.

5 AC0: Serie A, carp. 7, n. 10.

6 ACO: Serie A, carp. 8, n. 14. Transcripción de CiRIACO MIGUEL VigiL, Colección Histórico-Diplomática del Ayuntamiento de Oviedo, Ayuntamiento, Oviedo, 1889, pp. 292293.

7 AC0: Serie A, carp. 14, n. 7

8 Archivo Municipal de Oviedo (en adelante, AMO): Acta del Ayuntamiento de 18 de julio de 1533 (A-4 f. 24v.-25r.). 
Igualmente, gozaba de algún privilegio, como se observa en la petición del mayordomo de fábrica de la parroquial iglesia de San Isidro, doctor Pedro Martínez, a la Ciudad para que le preste el dosel para mayor lucimiento del oficio que se celebraría el día del Santo titular, "y que pondría cuidado en que no se maltratase"; se le concedió "en atención á ser parroquia de las casas de Ayuntamiento, pero sin causar ejemplar, y que pusiese todo cuidado en que no se maltratase ni deteriorase so pena de que serán por cuenta del Sr. Dr. Pedro Martínez todos los daños que en el dicho dosel resultasen ${ }^{9}$.

También aparece en los documentos del Archivo Catedralicio, porque, ocasionalmente, el capellán de San Isidoro ejercía las funciones de abad de la Cofradía del Rey Casto, como sucedió con Cosme Ferrández (1409), Alfonso Martínez (1433) y Alfonso Ferrández (1446).

Asimismo, en la parroquia de San Isidoro tenía su sede la Cofradía y Hermandad de las Ánimas de Nuestra Señora de la Soledad, según nos indica un censo de 1708 "a favor de la Cofradía y Hermandad de Ánimas de Nuestra Señora de la Soledad, fundada en la parroquia de San Isidoro el Real de la ciudad de Oviedo» ${ }^{10}$, $y$, según Canella, también la Cofradía y alberguería de Santa María Magdalena ${ }^{11}$.

La parroquia ejercía de patrono de la capilla de San Roque y en ella, el párroco de San Isidoro decía misa cantada el día del santo, como consta en los libros de Acuerdos municipales ${ }^{12}$.

9 AM0: Acta del Ayuntamiento de 16 de marzo de 1723 (A-53 f. 37v.-38r.).

10 AM0: 1708, enero, 22. Censo de 50 ducados de principal y 16 reales y medio de réditos impuesto por Domingo Pantiga y Ana Madera, su mujer, a favor de la Cofradía y Hermandad de Ánimas de Nuestra Señora de la Soledad (B-80-14).

11 Fermín Canella y Secades, Oviedo: Guía, Est. Tip. De Vicente Brid, Oviedo, 1888, pp. 251-252.

12 AM0: Acta del Ayuntamiento de 5 de agosto de 1705 (A47 f. 170v.-171r.). Acta del Ayuntamiento de 12 de julio de 1720 (A-52 f. 107v.-108r.). La Cofradía de San Roque se funda en Oviedo a partir de un acuerdo de la Junta General del Principado, presentado en la sesión del Ayuntamiento de 2 de diciembre de 1598, que establecía que todos los procuradores que habían estado presentes en la última Junta propusieran a sus respectivos ayuntamientos "cuán conveniente y necesario» sería establecer una fiesta votiva en honor de San Roque como remedio de la enfermedad contagiosa de la peste existente en muchos lugares del Principado "por merecerlo nuestros pecados". El Ayuntamiento designa un representante para tratar dicho asunto, de forma que ese mismo mes, en la sesión del día 11, se lee un memorial del deán y cabildo con las Capitulaciones para la fundación de la Cofradía de San Roque, que son aprobadas, siendo la primera de estas capitulaciones el que las cofradías de San Roque y San

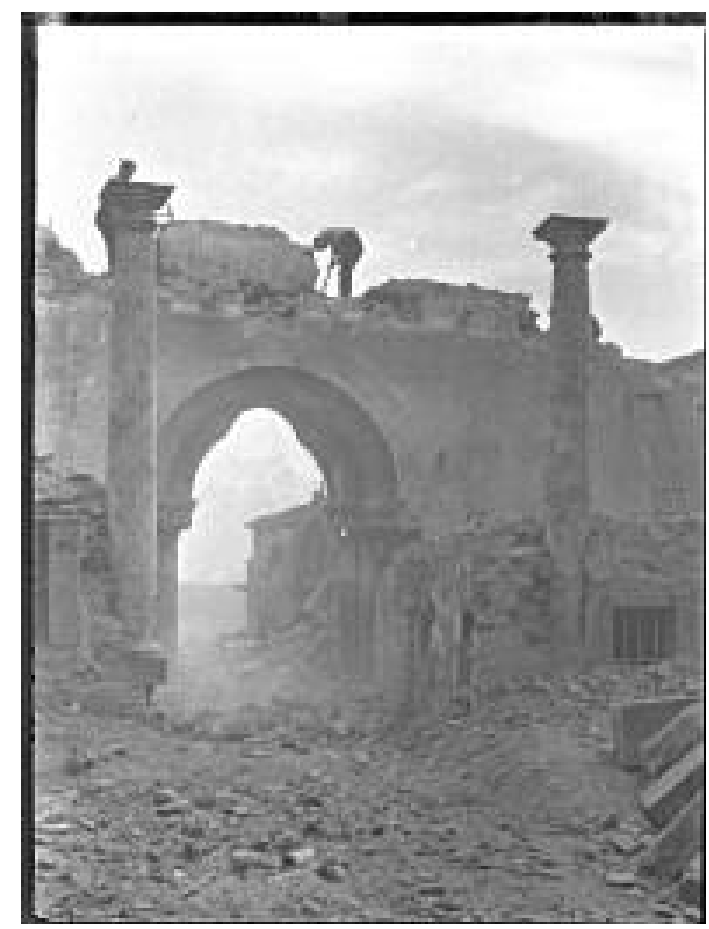

Fig. 1. Desmonte de la Iglesia de San Isidoro. 1922. AMO, Colección Armán. P0114.

Ya en el primer libro de Acuerdos Municipales de 1498 figuran en las reuniones del concejo «los representantes de la colación de San Isidorom (término que designa el territorio de cada parroquia).

Nada más se sabe del edificio, salvo alguna anotación, como la petición llevada a la sesión del Ayuntamiento de 14 de agosto de 1722, en la que expone que debido a que la predicación del padre fray Francisco Lavarejos en San Isidoro "conmovió los ánimos de los vecinos de la parroquia y otros», se recaudaron limosnas para obras en la iglesia parroquial, en dos capillas, y especialmente "para la devota imagen del Santo Cristo de la Misericordian. Visto lo cual se dirigen "a la piedad de la Ciudad" solicitando alguna contribución a dicha obra. La ciudad, acordó concurrir con 240 reales.

A raíz de la Pragmática Sanción de Carlos III de 1767 , se procedió a liquidar las pertenencias de la Compañía de Jesús en Oviedo. La necesidad de un nuevo templo parroquial para San Isidoro ante el estado del edificio y su insuficiente tamaño para tan poblada parroquia, llevó a solicitar la iglesia del Colegio de San Matías como nuevo templo parroquial, petición a la que accedió el Consejo Real en $1770^{13}$. En la sesión del

Sebastián han de ser "una misma» (A-13 f. 512 v. y 513v.514r.).

13 Justo García SÁnchez, Los Jesuitas en Asturias, IDEA, Oviedo, 1991, $372 \mathrm{pp}$. 
Ayuntamiento, de 10 de marzo de 1770, figura la siguiente anotación: "Al memorial dado por el Cura, Mayordomos y Comisarios de San Isidoro en que piden que la Ciudad se digne asistir a la traslación y fundación que han de hacer en la Iglesia de San Isidoro y en la nueva que fue de los expulsos. Y se acordó que la Ciudad aprecia la urbanidad y brindis que hacen dichos señores que está pronta a concurrir a una y otra en el día que cita y se nombre a los Señores Inclán y Vista Alegre para arreglar el modo de la concurrencia». El traslado se llevó a cabo, con gran ceremonial, el 16 de abril de $1770^{14}$.

\section{La secularización del templo}

El destino dado por el cabildo eclesiástico al edificio, ya sin uso eclesiástico, fue servir de tahona. En la sesión de 24 de diciembre de 1793 , el Ayuntamiento concedía una paja de agua a la tahona del cabildo, a condición de que sea solo por el tiempo en que esté la tahona, "trascendiendo el caño y agua afuera con su albergue para que también disfrute del beneficio el vecindario de aquel barrion y, como es lógico, que las obras sean a costa del cabildo catedralicio.

Ciriaco Miguel Vigil consigna el siguiente apunte del Libro de Acuerdos Municipales de 1820, su fecha 22 de septiembre: «Mándase retirar el agua de un caño existente en la Tahona, concedido por la Ciudad al Venerable Dean y Cabildo en 30 de Diciembre de 1793, á motivo de haber vendido el edificio á D. Manuel Secades» ${ }^{15}$. $\mathrm{Al}$ no conservarse los acuerdos de esas fechas, no se ha podido confirmar el dato. Lo que sí se sabe es que, unos años antes, Manuel Secades, vecino de esta ciudad y maestro de obras, por escritura fechada el 25 de julio de 1817, compró la casa de San Isidoro a los testamentarios de Félix de Bobes, cura de San Julián de los Prados. Dicha casa había sido entregada por el Ayuntamiento en foro perpetuo a Juan Crespo Hortelano, al que sucedió Pedro de Bobes, y por su muerte, su hijo, el mencionado doctor Félix de Bobes. Por lo que, en 26 de agosto de 1817, Manuel Secades otorgó escritura de reconocimiento de la misma a favor de la Justicia y Regimiento

14 Consta la publicación de un sermón del Dr. Juan González Villar y Fuertes, con fama de gran orador, sobre la Traslación de la iglesia parroquial de San Isidoro de Oviedo a la de la Compañía de Jesús.

15 Ciriaco Miguel Vigil, Colección Histórico-Diplomática del Ayuntamiento de Oviedo, Ayuntamiento, Oviedo, 1889, p. 426. del Ayuntamiento de Oviedo como dueños del directo dominio, comprometiéndose a pagar al Mayordomo de Propios y Rentas de la Ciudad el canon anual de 11 reales de vellón que estaba estipulado. Esta casa lindaba "y pegaba" con la muralla de la Ciudad, "por la delantera la Iglesia de San Isidoro, que hoy hace de Tahona con el azulejo no. 28", por arriba, con casa foral del Ayuntamiento y por abajo, con la calle pública y puerta donde estaba antes el arco del Postigo ${ }^{16}$.

Unos meses después, el 16 de octubre de 1817, el mismo Manuel Secades, por memorial de 5 de septiembre de 1817, expone que desde su casa, tras la Tahona señalada con el azulejo número 28 , hasta la muralla hay un espacio de pavimento que "se destina a deposito de inmundicias", por lo que solicita cerrar este hueco con pared y construir un piso principal guardando la línea de acera de calle. Ante el informe favorable del arquitecto de edificar casa y almacén "aprovechándose del grueso de muralla", se otorga escritura de foro perpetuo por el Ayuntamiento de Oviedo a favor de don Manuel Secades de un terreno de treinta y dos pies confinante con la muralla del Postigo haciendo frente a la Tahona, para construir por el canon anual de 22 reales, que se habían de pagar el día de San Martín, 11 de noviembre ${ }^{17}$. Por lo que podemos pensar que fuera el mismo Manuel Secades quien, poquito a poquito, se iba haciendo un hueco en la zona.

Manuel Secades fue un maestro de obras ovetense $^{18}$. En 1821 figura como Regidor del Ayuntamiento de Oviedo ${ }^{19}$ y aparece en los Padrones de vecinos de 1824 residiendo en la calle Postigo, para posteriormente, en 1831 y 1833, ya figurar con su familia en la calle San Isidoro $^{20}$. Permítaseme un paréntesis de genealogía familiar, precisamente de Manuel Secades; una de sus hijas menores, Carlota, contraerá matrimonio con Benito Canella, Secretario de la Uni-

16 AMO: D-21-14.

17 AMO: D-21-16.

18 «SECADES, MANUEL. Maestro de obras ovetense que trabajó por toda Asturias a caballo entre el siglo XVIII y XIX, fue el ejecutor material de las obras de Pedro Arnal: San Pedro de Coballes (1795) y San Andrés de Agues (1804) y proyectó otras edificaciones religiosas. Obras: En Caso: Nueva Sacristía de Santa María de Tanes (1807) en Sobrescobio: San Andrés de Soto de Agues (1804)" JoAQUín ARANDA IRIARTE, Autores de arquitectura en Asturias, Gijón, 2011, p. 312.

19 AMO: Regulación de las valías de granos y legumbres hecha por el Regidor del Ayuntamiento, don Manuel Secades, el día 7 de noviembre de 1821 (B-116 f. 245-247v.). Libro de Acuerdos municipales de 1821 (A-125).

20 AM0: B-51-2, B-52-1 y B-53-2. 
versidad, el 8 de mayo de 1845 en la parroquia de San Isidoro, y de esa unión nacerá, el 7 de julio de 1849 en la calle de San Francisco, 15, un niño al que pusieron los nombres de Fermín Pablo Ramón. Fermín Canella y Secades (Oviedo, 1849 - Oviedo, 1924) será, con el tiempo, uno de los intelectuales asturianos más ilustres. Desde sus cargos de Cronista Oficial de Asturias y de Oviedo, y de Miembro de la Comisión Provincial de Monumentos, de la que fue Secretario (1870-1898), Vice-Presidente (1898-1918) y Presidente (1918-1924) será una figura decisiva en la defensa del Patrimonio asturiano, curiosamente, entre otros, de los restos de la iglesia de San Isidoro $^{21}$.

Hay que señalar que en el Padrón de vecinos de 1833, la calle de San Isidoro pasa a recibir el nombre de "Tahona" y que recupera el nombre original de San Isidoro, en la sesión del Ayuntamiento de 7 de agosto de $1869^{22}$.

Y saltamos en el tiempo, al no tener más noticias hasta que, con fecha 28 de septiembre de 1917, Policarpo Herrero, en su calidad de Presidente de la Junta de la Cocina Económica de Oviedo se dirige al Ayuntamiento y, visto que se terminaba el plazo de la concesión a dicho establecimiento benéfico del solar propiedad municipal en la calle Quintana, cedido en junio de 1893 por veinte años, y que el Ayuntamiento no mostraba signo alguno de cederlo gratuitamente a la institución, propone que se permute dicho solar por el inmueble que esa Junta poseía en la calle San Isidoro, antes tahona, antes Iglesia de San Isidoro, y que habían adquirido por escritura de 28 de junio de 1911 ante el notario D. Cipriano A. Pedrosa, inscrita en el Registro de la Propiedad de Oviedo en 29 de agosto de 1911. El arquitecto municipal Julio Galán informa de la conveniencia de dicha permuta y efectúa una valoración de los terrenos: San Isidoro, 853,27 $\mathrm{m}^{2}, 17.695$ pesetas coste de su compra en 1911 . Solar en Quintana, $333 \mathrm{~m}^{2}$, con un valor de 9.665 pesetas solar y 9.000 pesetas el edificio. Asimismo, tasa los costes por un total de 27.000 pesetas: demolición (1.700 pesetas), desescombro (4.300 pesetas) y pavimentación de la plazuela resultante (21.000 pesetas) ${ }^{23}$.

Efectivamente, en el Padrón de vecinos de 1917, figuraban las casas de San Isidoro números 9 y 11 como pertenecientes a la Cocina Económica, mientras que el edificio al que se refieren en la calle Quintana es el que ocuparía el

21 AM0: Libros de Registro Civil 1845, R-5, y 1849, R-9.

22 AMO: A-153 f. 181r.-v.

23 AMO: 1-1-7-35.

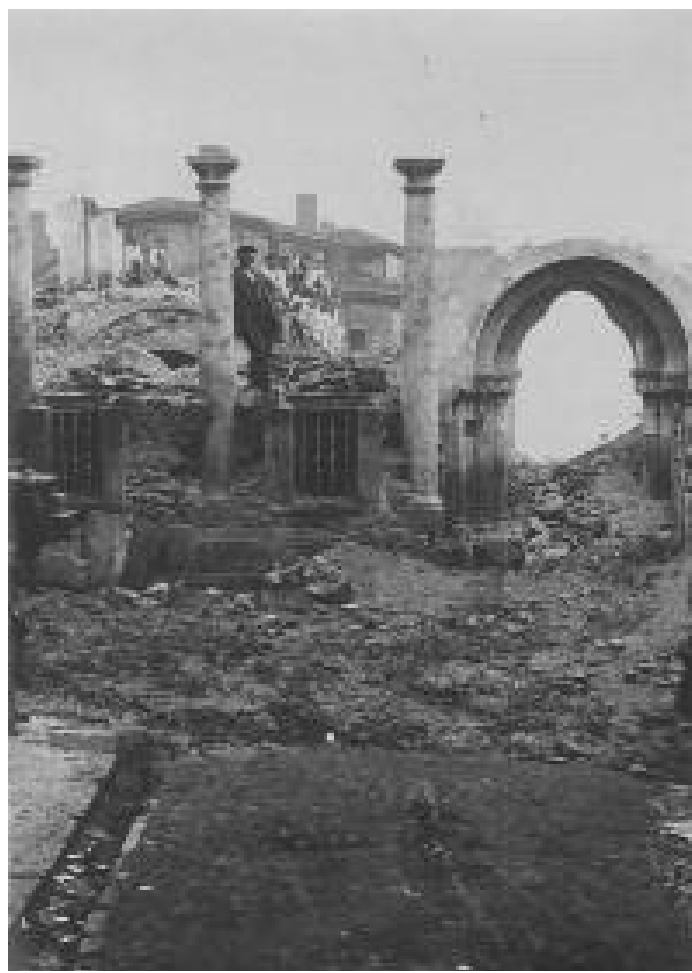

Fig. 2. Desmonte de la Iglesia de San Isidoro. 1922. Biblioteca de Asturias. Fondo Canella. Depósito de la familia Tolivar Alas. 3-38.

lugar del actual inmueble de Quintana, 2, más tres metros de fachada del edificio colindante y quine metros más de fondo.

La permuta se aprueba en la sesión de 22 de marzo de 1918 con las siguientes condiciones: "siempre que la Junta de la Cocina Económica por su cuenta se encargue de la demolición del referido edificio, y de la pavimentación del espacio que queda para plazuela. Como con la desaparición del precitado edificio se sanea toda aquella zona y mejoran notablemente los edificios inmediatos, debe requerirse a los propietarios de los edificios a quienes afecte la mejora, por si voluntariamente quieren contribuir con alguna cantidad a los fondos municipales. En otro caso, y con arreglo a la Ley de las Haciendas locales debe pasar este asunto a la Comisión de Hacienda para que con arreglo a lo dispuesto en la misma, fije la cantidad con que deben contribuir los citados propietarios por dicha mejora». Por otra parte, se puntualiza que «debe ponerse como condición en la escritura que se otorgue, que el día que los locales dejen de prestar servicio para la Cocina Económica pasen a ser propiedad otra vez del Ayuntamiento abonando éste el precio en que fue adquirido el edificio de la calle de San Isidoro".

Por dos veces, en 25 de marzo de 1918 y en 17 de julio de 1919, se comunica a la Presiden- 
cia de la Cocina Económica el acuerdo tomado; al no recibir respuesta, se le requiere contestación, con carácter de urgencia, el 3 de marzo de 1921, sin que figure tampoco contestación alguna en el expediente ${ }^{24}$. En las actas municipales figuran varias preguntas de concejales al respecto en estos años, llegando incluso el Alcalde, don Marcelino Fernández, a entrevistarse con el administrador de la Cocina Económica para exponerle el riesgo que presentaba el edificio habitado ilegalmente y con peligro de derrumbe ${ }^{25}$.

Ante la falta de respuesta, el Ayuntamiento retoma la cuestión modificando las condiciones establecidas, y así, en la sesión del Ayuntamiento de 22 de abril de 1921 se aprueba la modificación de lo acordado en 1918 para la demolición de "la iglesia de San Isidoro»: la demolición y pavimentación serían por cuenta del Ayuntamiento y sigue como precio para la reversión del edificio de Quintana, las 17.695 pesetas que le había costado el edificio que se trata de demoler.

En el expediente número 64/1946 ${ }^{26}$ de «Reversión al Patrimonio Municipal del edificio que ocupa la Cocina Económica en la calle Quintana", se encuentran las copias de los escritos y oficios intercambiados entre el Ayuntamiento y la Cocina Económica sobre esta cuestión, documentos que se encontraban en los archivos de la Junta de la Cocina Económica. Además del oficio del Ayuntamiento de Oviedo de 3 de marzo de 1921 (al que se comprueba que tampoco contestaron, ya que no consta escrito alguno), figura el oficio municipal de 28 de abril de 1921 con las nuevas condiciones y la contestación de la Junta de la Cocina Económica en un escrito de 11 de mayo de 1921 aceptando las condiciones de la permuta. Para la tramitación de la permuta el Ayuntamiento reclama a la Cocina Económica, con fecha 26 de octubre de 1921, la escritura de compra de la iglesia de San Isidoro, escritura que es diligentemente enviada el 28 de octubre de 1921, aunque no se conserva en el expediente.

En la sesión del Ayuntamiento, de 7 de enero de 1922, se da noticia de la Real Orden de 30 de noviembre de 1921 autorizando la permuta del edificio que ocupa la Cocina Económica por la antigua iglesia de San Isidoro. La Real Orden ofrece información muy interesante sobre los dos edificios: "en el expediente aparece justificada la propiedad a favor del Ayuntamiento del te-

\footnotetext{
24 AM0: 1-1-7-35.

25 AM0: Acta del Ayuntamiento de 25 de octubre de 1918 (A-204 f. 186r.).

26 AMO: 10-3-78-2.
}

rreno que ocupa la Cocina Económica toda vez que éste formaba parte de las casas números 10 y 12 de la calle de los Arcos de los Zapatos que fueron adquiridas por la Corporación municipal, en virtud de expropiación forzosa a los señores Menéndez de Luarca y Aloutas la del número diez y la del doce a Don Juan Suárez, para ensanche de la calle de Quintana y la propiedad del inmueble que la Cocina Económica ofrece en permuta, se acredita mediante la escritura de compra por dicha entidad a Doña Teresa Secades, hecha en 28 de Junio de 1911, y que practicadas las operaciones de la situación, cabida, y tasación de los edificios objeto de la permuta da ésta última 17.696,00 [sic] pesetas, la Iglesia de San Isidoro y construcciones adosadas, y 18.665,00 pesetas el edificio de la calle de Quintana".

No es difícil suponer que Teresa Secades y González Caces, tal como figura en el Registro de la Propiedad, fuera heredera de aquel lejano Manuel Secades que vimos adquiriendo diversos inmuebles en San Isidoro, entre ellos la tahona.

Como curiosidad puntualizaremos que, cuando en 1944 la Cocina Económica se plantea abandonar el edificio de Quintana siguiendo los términos establecidos en la escritura, la propiedad del edificio revierte en el Ayuntamiento a cambio de las 17.695 pesetas del coste del edificio en $1911^{27}$. Hay que consignar que, asimismo, dado el carácter benéfico de dicha institución, el Ayuntamiento otorga, con carácter extraordinario, una subvención de 57.300 pesetas para las obras de construcción del nuevo edificio.

La escritura de permuta de los terrenos no se conserva y, de hecho, existen oficios del Ayuntamiento dirigidos a las notarías de la ciudad solicitando la búsqueda de dicha escritura, informes, todos ellos contestados de forma negativa. Igualmente en el Registro de la Propiedad no figura la inscripción del inmueble a nombre del Ayuntamiento de Oviedo, siendo la última anotación la correspondiente a la venta a favor de la Cocina Económica en 1911.

\section{El derribo}

Y, en estos momentos, hace presencia en escena un nuevo personaje. En la sesión del Ayuntamiento de 27 de enero de 1922 consta una ins-

\footnotetext{
27 AMO: Acta de Reversión de 31 de mayo de 1946. Expte. 64/1946 (10-3-78-2).
} 
tancia presentada por el presidente de la "Sociedad Cooperativa de Armeros para la construcción de casas baratas» solicitando permiso para efectuar el derribo del caserón conocido como antigua Iglesia de San Isidoro por su cuenta y riesgo, con el fin de aprovechar los materiales resultantes. El Arquitecto y la Comisión acuerdan acceder a lo solicitado con las siguientes condiciones: $1^{a}$ Designación de un director facultativo y comunicación del mismo al Ayuntamiento para la emisión de la oportuna licencia; $2^{\text {a }}$ una vez comenzada la demolición, no se podrá interrumpir hasta dejar el solar completamente limpio de materiales y escombros; $3^{\mathrm{a}}$ los trabajos durarán un máximo de 180 días a contar desde la emisión de la licencia; $4^{\text {a }}$ depósito de 2.000 pesetas en calidad de garantía; $5^{\mathrm{a}}$ instalación de una valla de seguridad antes de comenzar el derribo; $6^{\mathrm{a}}$ no se permitirá arrojar escombros a la calle desde lo alto; $7^{\text {a }}$ no se arrimarán los escombros a la valla ni se depositarán en la vía pública; $8^{\mathrm{a}}$ se transportarán por las calles de San Isidoro y Postigo a los vertederos que el Ayuntamiento disponga; y 9a cualquier accidente o suceso que ocurra será responsabilidad de la Sociedad.

La citada Cooperativa había obtenido las licencias para la construcción de un grupo de casas baratas en el Campo de los Patos, esquina a la Carretera de Gijón (actual calle Adelantado de la Florida), con fecha 2 de diciembre de 1921 (una casa pareada con dos viviendas), y 20 de enero de 1922 (las siete casas pareadas restantes con catorce viviendas), con planos firmados por el arquitecto Julio Galán, en Oviedo, a 14 de julio de 1921. Este grupo de casas, que todavía se conservan, es conocido como la Colonia de San Feliz al erigirse sobre un solar donado por don Antonio de Sarri y Oller, Marqués de San Feliz. Dado que el mismo arquitecto que firma los planos, Julio Galán, es el arquitecto municipal que tasó el derribo de San Isidoro, no es muy aventurado sospechar que de él partió la idea de solicitar la ejecución del derribo para aprovechar los materiales.

Lo que sucedió con el derribo y los materiales viene a ser una incógnita, aunque afortunadamente se conserva documentación gráfica del desmonte (figs. 1, 2, 3 y 4).

\section{Las inscripciones en sus muros}

Entre las imágenes del desmonte de la Iglesia que se encuentran en el Fondo Canella de la Biblioteca de Asturias, hay varias de las

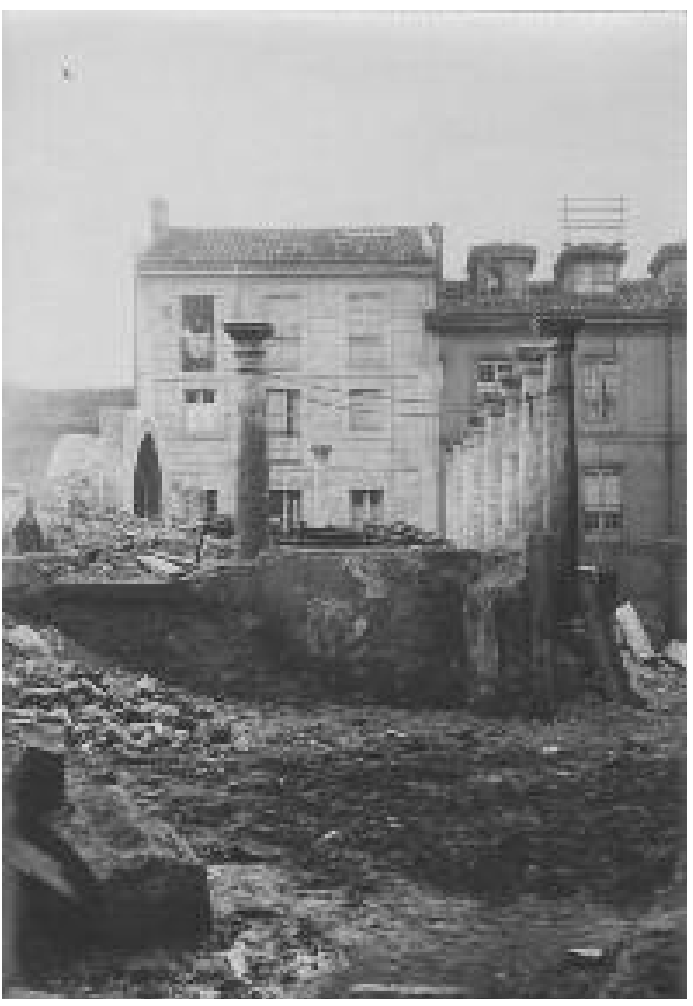

Fig. 3. Desmonte de la Iglesia de San Isidoro. 1922. Biblioteca de Asturias. Fondo Canella. Depósito de la familia Tolivar Alas. 3-38.

paredes interiores de la Iglesia en las que se aprecian inscripciones, a manera de "vítores". Entre los nombres, que las fotografías nos han permitido descifrar, podemos destacar los siguientes $^{28}$ :

- Doctor don Tomás de Serrano de Paz. Abogado y regidor de esta Ciudad. Catedrático de Prima de Cánones y Leyes, y Vicerrector en los años 1671 y $1674^{29}$. Empadronado en la Puerta Nueva, feligresía de San Isidoro en 1686 y $1692^{30}$.

- Doctor don Diego Antonio Serrano de Paz y Quirós. Médico Catedrático y Médico de la Ciudad (1697-1706). Hijo del Doctor don Tomás de Serrano de Paz. Empadronado en la Puerta Nueva en 1686 y en Santo Domingo en 1705, ambas de la parroquia de San Isidoro. A

28 Quiero expresar mi agradecimiento en esta búsqueda a don Justo García Sánchez, gran estudioso y conocedor como nadie de la historia de la Facultad de Derecho de la Universidad de Oviedo.

29 Fermín Canella y Secades, Historia de la Universidad de Oviedo y noticias de los establecimientos de enseñanza de su distrito, $2^{\text {a }}$ ed., Imprenta de Flórez, Gusano y Compañía, Oviedo, 1903, p. 679.

30 AM0: B-43-2 f. 22 r. y B-43-3 f. 22 v. 
partir de 1705 la Ciudad le concede en foro por doscientos años la casa de la Plaza Mayor comprometiéndose a arreglarla a sus expensas ${ }^{31}$.

- Doctor don Francisco Fernández Sabido. Abogado, Catedrático de Prima de Cánones y Regidor de Oviedo. En 1686 vivía en la calle de la Ferrería, parroquia de San Isidoro junto con sus hijos Francisco y Diego, para posteriormente trasladarse a la zona de la Plazuela de la Catedral, feligresía de San Tirso, hasta su fallecimiento en $1722^{32}$.

- Doctor don Francisco Fernández Sabido Cartavio. Catedrático de Instituta. Hijo de Francisco Fernández Sabido. Empadronado en la misma casa que su padre hasta su fallecimiento, que fue cuatro años antes que el de su progenitor, dejando viuda, Manuela Muñiz Miranda, y un hijo, Francisco Antonio ${ }^{33}$.

- Doctor don Pedro Fernández Palacio Argüelles. Catedrático de Prima de Leyes, Canónigo doctoral en la Santa Iglesia, Catedrático de Prima de Cánones y Rector en $1699^{34}$. Empadronado en la calle de Santo Domingo en 1686, 1692 y $1698^{35}$.

- Padre Maestro Silva. Benedictino, Regente de San Vicente y Catedrático de Teología de la Universidad de Oviedo (en 1664 Catedrático de Escritura, y en 1667 Catedrático de Vísperas) ${ }^{36}$.

31 AM0: Acuerdo 28 de enero de 1697 (A-44 f. 24v-25r.); Acuerdo 29 de julio de 1705 (A-47 f. 165v-166r); B-432 f. 22 r.; B-44-1 f. 33 r.; D-18-32 f. 47r.-96v. y Acta de la sesión de Ayuntamiento extraordinario de 24 de enero de 1707 A-48 f. $23 \mathrm{v}$.

32 AMO: B-43-2-2; B-25-2 f. 616-626; B-43-4 f. 10v.; B-451 f. 21 r.; B-43-2 f. 23v. y B-44-3 f. 6r. Archivo Histórico Diocesano de Oviedo: Parroquia de San Tirso. Sign. 39.15.20, difuntos, Fol. 100r.

33 AMO: B-43-2-2; B-25-2 f. 616-626; B-43-4 f. 10v.; B-451 f. 21r.; B-43-2 f. 23v.; B-44-3 f. 6r. y B-44-4 f. 13r. Archivo Histórico Diocesano de Oviedo: Parroquia de San Tirso. Sign. 39.15.20, difuntos, Fol. 88r.

34 Fermín Canella y Secades, Historia de la Universidad de Oviedo y noticias de los establecimientos de enseñanza de su distrito, $2^{\mathrm{a}}$ ed., Imprenta de Flórez, Gusano y Compañía, Oviedo, 1903, p. 677.

35 AMO: B-43-2 f. 33r.; B-43-3 f. 37r. y B-43-3 f. 26v. Consta como empadronador en 1705 (B-44-1 f. 20v.).

36 P. FR. JuAn TABOADA, OP, Historia del Convento de Nuestra Señora del Rosario de Oviedo, San Esteban y Real Instituto de Estudios Asturianos, Salamanca, 2002, pp. 488489.

\section{El solar}

Respecto al destino del solar, dos años después, una moción en la sesión de la Comisión Permanente de 3 de julio de 1924 insta al arquitecto municipal a proceder con urgencia en la confección de un proyecto que establezca en los terrenos procedentes del derribo del caserón de San Isidoro, los puestos de frutas, hortalizas, granos, etc. para "descongestionar" la Plaza del Fontán y Trascorrales, sin que se sepa más del proyecto.

Sin embargo, una instancia de Isidro Maraña y José María Suárez solicitando permiso para construir en el solar un cinematógrafo, hace que, de nuevo, vuelva a primer plano el debate sobre San Isidoro que parecía ya cerrado ${ }^{37}$. Las razones esgrimidas para la construcción del edificio son tan peculiares $y$, a veces, tan peregrinas, que no me resisto a su transcripción:

«Es evidente que el acrecimiento de las riquezas sociales ha hecho que la antigua y congestionada población de Oviedo se extendiera por todos lados abriendo nuevas y espaciosas vías públicas en las que se elevaren suntuosas edificaciones y en las que hoy se vive con más aire, más sol y más higiene, factores poderosísimos del fortalecimiento de la razón.

Y, respondiendo a una ley natural, en busca del aire, del sol, de la higiene y de los edificios hermosos se desplazó lo que antes permanecía agobiado en el Oviedo antiguo: comercio, bancas, oficinas públicas y privadas, círculos de recreo, cafés, bares, centros culturales y musicales y absolutamente todos los espectáculos públicos donde el pueblo se solaza y adquiere más o menos cultura.

El Oviedo antiguo, el clásico, especialmente los barrios populares como el de Santo Domingo, Postigos Alto y Bajo, Tenderina, Vega, quedaron aislados de la población llena de luz y de alegría y cuando sus vecinos desean acudir a cualquier espectáculo teatral o cinematográfico vense obligados a emplear en ello más tiempo del que quieren porque, además de ser larga la distancia, creen que les es necesario, para ir allá algo más que el aseo personal y la limpieza: el lujo.

Pues en el corazón de esos barrios populosos, o, si no en el corazón, en sitio estratégico, posee el Excmo. Ayuntamiento de Oviedo un terreno en el cual se levantaba el Convento [sic] de San Isidoro, que, por hallarse ruinoso y constituir un peligro, fue derribado con el aplauso ge-

\footnotetext{
37 AMO: Expte. 166/1925 (4-5-36-3).
} 


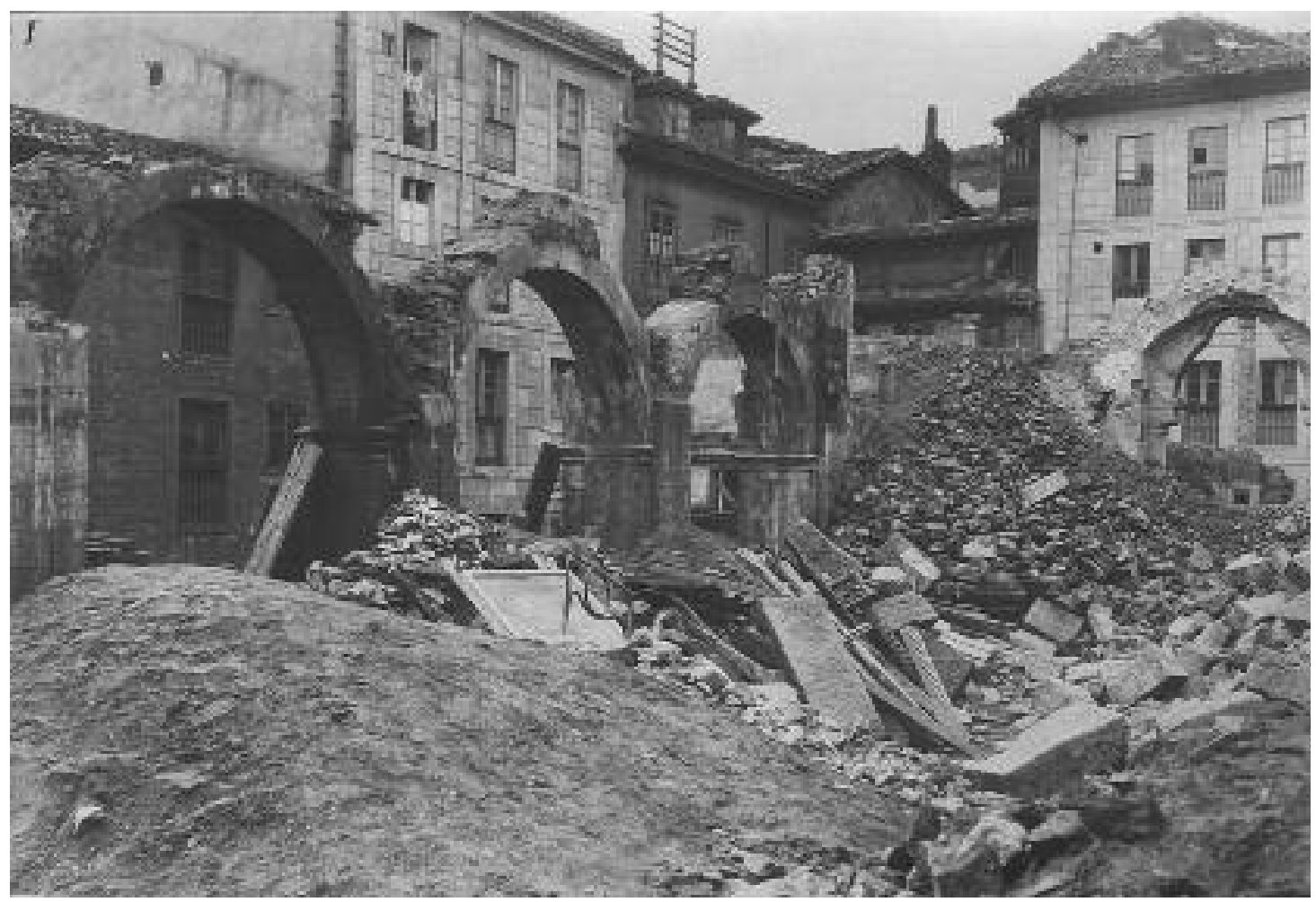

Fig. 4. Desmonte de la Iglesia de San Isidoro. 1922. Biblioteca de Asturias. Fondo Canella. Depósito de la familia Tolivar Alas. 3-38.

neral del pueblo ovetense. Aquel lugar parece reclamar que le hermoseen y que le hagan útil al vecindario, proporcionando a este algo espiritual, algo así como lo que hay en la zona rica, donde hay aire, sol e higiene, algo que de al pueblo, $\mathrm{y}$, especialmente, a las clases trabajadoras sensibilidad artística, tan indispensable al hombre fiel cumplidor de sus deberes sociales.

Discurriendo así y basándonos en estas consideraciones y en otras muchas que no hacemos constar por la ya excesiva extensión de este escrito,

SOLICITAMOS de la Excma. Corporación $\mathrm{Mu}-$ nicipal de Oviedo, y siempre con el respeto debido, el necesario consentimiento para construir en el terreno citado un edificio que se destinaría a proyectar cintas cinematográficas y exponer varietés con toda clase de espectáculos teatrales cultos, instalando, además, en lugar adecuado, un puesto de expedición de caramelos y dulces y refrescos, exceptuando en absoluto [sic] la venta de alcoholes."

Y, por si existian dudas sobre su carácter benéfico y filantrópico, los solicitantes hacían la siguiente oferta:

«Interesado en que el proyectado salón de espectáculos adquiera carácter eminentemente popular, y por ser nosotros entusiastas amantes de la infancia, desde luego nos comprometemos a conceder libre y gratuita entrada, una vez al año, celebrando, con ese motivo, una fiesta infantil, a todos los niños y las niñas que asistan a las Escuelas municipales establecidas en los barrios citados, y a celebrar otra fiesta anual y suntuosa, con entrada de pago, a beneficio de las Colonias escolares."

No parece que el arquitecto municipal, Francisco Casariego, se dejara seducir por estos cantos de sirena y las promesas de aire, sol, higiene y alegría que el edificio, y su expendedor de alimentos, iban a aportar a la, supuestamente, maltratada zona, al contrario, en un meditado informe, con fecha 13 de julio de 1925, pone sobre la mesa una serie de cuestiones que van directas al meollo de la cuestión. He aquí el informe:

"La índole de la cuestión que los Sres. Maraña y Suarez someten a la consideración del Ayuntamiento, que se sale del campo puramente técnico, invitan al que suscribe á concretar el informe que se le pide a la presentación de un cuestionario con los extremos sobre los que a mi juicio debe meditar el Ayuntamiento para conceder ó denegar la autorización que dichos Sres. solicitan.

1. Razones que hubo para demoler la antigua Iglesia de S. Isidoro.

2. Destino o destinos en que hasta ahora se pensó podría tener el solar de la 
antigua Iglesia y destinos que pudiera tener.

3. Si las razones que exponen los interesados y otras que pudiera haber, declaran aceptable que se dé a la plaza el destino que se pide.

4. Superficie con relación a la total que en caso afirmativo podría cederse de la plaza para tal fin y altura máxima aceptable para el edificio.

5. Si el arco que hoy allí existe, único resto de la antigua Iglesia, debe permanecer allí o es oportuno su traslado y por cuenta de quién y nuevo lugar para su emplazamiento.

6. En qué condiciones habría de quedar el resto del solar que no fuera ocupado por el edificio y por cuenta de quién serían las obras.

7. Número de años que debería durar la concesión, renta anual y si al cabo de un cierto tiempo debiera o no pasar a propiedad municipal el edificio cinematógrafo con sus anejos.

8. Manera de que la determinación del Ayuntamiento esté en consonancia con la opinión de los vecinos de la zona en que se pretende emplazar el cinematógrafo."

Y entre estas cuestiones planteadas, hay una que sorprende sobremanera: "Si el arco que hoy allí existe, único resto de la antigua Iglesia....". Luego, la demolición no fue total y, en 1925, quedaba un arco testimonio de la antigua iglesia románica ${ }^{38}$.

\section{El arco superviviente}

A estas cuestiones, la Comisión de Policía Urbana contestó en forma con fecha 18 de agosto del mismo año ${ }^{39}$. La Comisión extracta el expediente de demolición de San Isidoro, con la

38 Para un estudio del arco de San Isidoro y su papel dentro de la arquitectura románica asturiana, véase ADRIANA CarRILes García, "Iglesia de San Isidoro", en Enciclopedia del románico en Asturias, dirección, Miguel Ángel García Guinea, José María Pérez González; coordinación, María Soledad Álvarez Martínez, Fundación Santa María la Real, Centro de Estudios del Románico, Aguilar de Campoo (Palencia), 2006, v. II, pp. 658-660; y Ma SolEdad Álvarez Martinez, El románico en Asturias, Trea, Gijón, 1999, pp. 118-122.

39 En agosto de 1925 formaban la Comisión de Policía Urbana los concejales Luis Botas Rodríguez, Gerardo Berjano Prieto, Manuel Gallego Velasco, Antero Suárez Coronas, José María González Valle, Jose María García solicitud de la Sociedad Cooperativa de Armeros, los informes del arquitecto municipal y los acuerdos del Ayuntamiento, todos ellos de 1922, y llega a la conclusión de que la principal razón para el derribo del edificio fue, ante su estado ruinoso, el ensanche de la zona, por lo que lo único que debería hacerse sería acondicionar el pavimento "en forma que permita a los niños jugar con toda libertad» e, incluso, habilitar una pared medianera como frontón. Por otra parte, la Comisión se permite observar, frente a las razones de Maraña y Suárez, que los cinematógrafos suelen ser poco higiénicos y en ellos «no se cultiva el espíritu de los niños sino más bien al contrarion y en lo que podríamos considerar un refinado ataque directo escriben: «Respecto a cultura y sensibilidad artística tan solo haremos observar que de lo que se trata es de levantar un cinematógrafo en el solar obtenido por derribo de una iglesia románican. No se puede decir más alto, ni más claro. Por último, en relación con el arco existente deciden que sea objeto de una moción aparte.

Como era de esperar, este informe llevó a la Comisión Permanente a denegar la solicitud de construcción del cinematógrafo en su sesión de 17 de septiembre de 1925.

Que la Comisión de Policía Urbana era «de armas tomar" queda manifiesto en el texto de la moción $^{40}$ que presentan el mismo día 18 de agosto para el traslado del arco sito en la explanada de la plaza de San Isidoro. La moción dice lo siguiente (la cursiva es mía):

«En Enero de 1922 acordó el Ayuntamiento de Oviedo la demolición total y absoluta de la antigua Iglesia de San Isidoro, sin tener en cuenta para nada ni su remota antigüedad ni su gran mérito artístico y arqueológico. Con un simple informe del estado de ruina a que había llegado la mayor parte del edificio, a causa del abandono en que se hallaba, y sin hacer averigua-

Guisasola y Ramón Suárez Pazos. De acuerdo con el Estatuto municipal, promulgado por Real Decreto-Ley de 8 de marzo de 1924 durante la Dictadura de Primo de Rivera, en los municipios de más de 1.000 habitantes coexistian dos tipos de concejales: Concejales de elección popular y Concejales de representación corporativa, éstos últimos designados por las Corporaciones o Asociaciones que figuraran en un Censo especial que al efecto se instituyó (art. 43). Dado que las elecciones populares no se llegaron a celebrar, en la práctica los concejales de elección popular fueron directamente nombrados por los gobernadores civiles. $\mathrm{Y}$ así fue con los concejales que formaban esta Comisión de Policía Urbana, salvo el caso de Jose María García Guisasola, concejal de elección corporativa designado por la Cámara Agrícola Provincial.

40 AMO: Expte. 175/1925 (4-5-36-16). 
ciones acerca de una posible restauración y consolidación que hubieran permitido el darle algún fin de utilidad, como por ejemplo la instalación del museo arqueológico, se autorizó a una cooperativa de casas baratas para proceder a su derribo con una serie de condiciones una de las cuales (la 2a) decía textualmente:

"Una vez empezada la demolición no podrá suspenderse por ningún motivo hasta dejar el solar, donde dicho caserón está enclavado, completamente limpio de toda clase de materiales y escombros"

Esta resolución, digna de los mejores tiempos de Atila, movió a un grupo de verdaderos amantes de Oviedo, entre los cuales figuraban algunos señores que hoy día forman parte de esa dignísima Comisión Permanente y con ellos el excepcional Alcalde Sr. Ladreda a adquirir la bella portada de la Iglesia y regalarla al pueblo de Oviedo por medio del Excelentísimo Ayuntamiento que acordara su desaparición. El arco se encuentra ahora en medio de una pretendida explanada incitando al transeúnte a la averiguación de las causas de semejante espectáculo y los consiguientes comentarios en evitación de lo cual los concejales que suscriben tienen el honor de proponer a esa Comisión sea trasladado dicho arco a la Iglesia de San Tirso el Real, para que sirva de portada de ingreso por la plaza de Alfonso II el Casto, abonándose los gastos por partes iguales entre el Ayuntamiento y la parroquia de San Tirso".

Este escrito nos aclara la causa de la permanencia del arco, ni más ni menos que su adquisión por parte de un grupo de ovetenses para evitar su destrucción. Se trata del Centro de Estudios Asturianos y qué mejor presentación de la institución que la que el propio José María Fernández-Ladreda (Oviedo, 1885 - Siero, 1954) hace de ellos mismos en el primer número de su Boletin ${ }^{41}$ :

"Cuatro asturianos entusiastas, el Conde de la Vega del Sella, el Marqués de la Rodriga, D. Aurelio de Llano y D. Juan Uría Ríu tuvieron el acierto a finales del año 1918 de coincidir en el pensamiento de la necesidad de crear en nuestra región un CENTRO dE EsTUdios AstuRIANOS... la apatía tan íntimamente unida a la vida asturiana, hizo que la idea no fuera realidad hasta dos años después, fecha en que se celebró una gran reunión en el Paraninfo de la Universidad con-

41 José MARÍA FeRnÁNDEZ LADREDA, "Cuatro palabras para dar a conocer a los lectores su nacimiento y actuación», en Boletín del Centro de Estudios Asturianos, Año I, n. 1, Oviedo, 1924, pp. 42-45. vocada por el Delegado Regio de Bellas Artes y en ella quedó fundado el CENTRO y nombrada su Junta Directiva.

Organizado el Centro en Secciones Artes Plásticas, Música, Historia, Literatura, Ciencias jurídicas, Económicas y sociales y Ciencias de aplicación, continúa su silenciosa pero interesante labor y amante de los tesoros asturianos, vigilando con celoso cuidado su conservación, con escasos recursos, procura sin embargo no se lleve a cabo la demolición del arco de entrada de la antigua Iglesia de San Isidoro y lo adquiere de la Sociedad de armeros, rogando al Ayuntamiento se ocupe de su conservación".

De la importancia de este Centro y la categoría de sus miembros, con echar un vistazo a la lista de socios en 1924 tenemos sobrada respuesta; a manera de muestra el Presidente honorario era don Fermín Canella Secades, y entre sus miembros figuraban don Rogelio Jove y Bravo, don Leopoldo Alas, don Aurelio de Llano, el señor Marqués de la Rodriga, don Juan Uría Ríu, don Víctor Hevia, don José María Fernández Ladreda, etc.

Cuándo y cómo fue adquirido el arco y el precio de compra no consta en ningún documento; siempre se habla del Centro de Estudios Asturianos como su propietario pero sin aportar más datos. El hecho de que en el artículo de presentación de este Centro se hable de la compra efectuada a la Sociedad de Armeros puede explicarnos la causa de que ni en los Libros de Actas municipales de esos años, ni en los Libros Diarios de Ingresos de 1922 exista constancia de dicha compra: el negocio discurría entre las dos sociedades privadas.

La moción se presenta a la sesión de la Comisión Permanente de 20 de agosto de 1925; el alcalde Ladreda puntualiza a la misma que, al ser el Centro de Estudios Asturianos el propietario, habría que consultarles el lugar más apropiado para su colocación, asimismo, se permite recordar que el señor Marqués de la Rodriga ${ }^{42}$ era de la opinión de que se instalase en el Campo de San Francisco (curiosamente, el Marqués de la Rodriga estaba presente en esta sesión al

42 Manuel González-Longoria y Leal-Cuervo y Barrera, abogado ovetense, fue el primer Marqués de la Rodriga, (Oviedo, circa 1870 - Oviedo, 1943). El Marquesado de la Rodriga es un título nobiliario español, creado el 20 de abril de 1895, por la reina regente María Cristina de HabsburgoLorena, y otorgado a D. Manuel González-Longoria y Cuervo, por sus servicios como Senador del Reino, con la particularidad de que el título lo ostentaría su primogénito en vez de él, de ahí la frecuente confusión entre el padre y el hijo. 
ser concejal del Ayuntamiento). La Comisión acuerda lo propuesto por el alcalde de dirigirse al presidente del Centro de Estudios Asturianos.

De lo hablado no queda constancia, pero en el ya citado expediente 175/1925 figura una moción del alcalde de 6 de septiembre de 1925 proponiendo la instalación del arco en el Campo de San Francisco y que se encargara su realización al escultor Víctor Hevia (Oviedo, 1885 - Oviedo, 1957), con un coste de 12.000 pesetas, según el presupuesto que adjunta, de fecha 4 de septiembre de 1925, y en el que indica las labores a realizar:

"Las obras que es necesario ejecutar son:

1. Varios croquis y plantas del arco numerando las piedras.

2. Desmontaje del arco, para lo que se requiere andamiaje y cerchas

3. Traslado de los materiales al campo de San Francisco

4. Montaje en lugar asignado en la forma en que se halla hoy.

5. Una vez montado restauración absolutamente necesaria para su conservación de algunas de sus partes.

6. Reconstrucción de la obra de sillería en que el arco va encuadrado, hoy ruinosa en casi su totalidad

7. Y por último, como obra imprescindible, para preservar el arco de la acción destructora de las lluvias, construcción de un remate en piedra a dos vertientes ajustado en todo al carácter arquitectónico del arco.

La restauración del arco consistirá en limpiar las piedras sin picarlas quitando la pintura que hoy oculta algunos finos detalles de ornamentación. Y con la reposición de varias piezas necesarias al efecto artístico tanto como a la solidez del arco. Operaciones que han de llevarse a cabo procurando siempre respetar el carácter del monumento y el sello de antigüedad que lo avalara.

En total, puede calcularse el costo de las obras en unas doce mil pesetas".

La moción es aprobada en la sesión de la Comisión Permanente de 10 de septiembre de 1925; también se aprueba una petición del Marqués de la Rodriga (en este caso, presentada directamente por él sin intermediarios) de solicitar la intervención de la Comisión de Monumentos y, ya de paso, que "se le pidan algunas columnas, arcos y una ventana desmenuzada, que yacen abandonadas en el Museo Arqueológico, para mon- tarlas en una avenida del Campo de San Francisco para su embellecimiento".

Probablemente, la causa de esta petición sean las alarmantes noticias aparecidas por esas fechas en la prensa regional, sobre el preocupante estado del pomposamente llamado Museo Asturiano de Antigüedades, un local oscuro en las Escuelas Normales donde se acumulan las antigüedades "en informe montón, cubiertas con un manto espeso de polvo y adornadas con hermosas redes que las arañas supieron tejer, hermosísimos capiteles, trozos de arco, muchas tejas romanas, elementos de piedra pulimentada, sarcófagos, pedernales, objetos de hierro y bronce, esculturas, escudos antiguos y otras muchas curiosidades" 43 .

Sin embargo, en la primera sesión que la Comisión Provincial de Monumentos lleva a cabo después de esta fecha (28 de octubre de 1925), no se menciona esta petición, por lo que, o bien no fue cursada, o bien la Comisión se abstuvo directamente de tratarla. Lo que resulta curioso puesto que en una sesión anterior, de 10 de junio de 1922, se comunican las noticias existentes sobre el derribo de la iglesia de San Isidoro y se acuerda estar «prevenidos", intentar adquirir los restos románicos, aunque se reconocen carentes de recursos, y obtener, cuanto menos, fotografias de lo existente para su conveniente estudio ${ }^{44}$.

La Comisión de Paseos y Arbolados consideró que el espacio más adecuado para su emplazamiento era el «lugar contiguo a la meseta que se encuentra próxima al espacio que ocupó el antiguo Lago", y allí se transportaron los materiales bajo la supervisión del sobrestante municipal, habiéndose abonado por dicho concepto 2.380 pesetas, satisfechas por libramiento expedido en 30 de noviembre de 1925, según consta en informe del interventor municipal, por lo que él mismo puntualiza que para la restauración del arco ya sólo queda disponible la cantidad de 9.620 pesetas. Lo que lleva a que la Comisión Permanente, en sesión de 3 de diciembre de 1925, acuerde comunicar a Víctor Hevia si acepta la restauración sin que su retribución exceda de dichas 9.620 pesetas.

La contestación no tarda en llegar y, el 6 de diciembre, Hevia se declara conforme con dicha cantidad. El expediente finaliza con la solicitud,

43 La Voz de Asturias, martes 26 de agosto de 1924. Información facilitada por don José Antonio Fernández de Córdoba.

44 Museo Arqueológico de Asturias (en adelante MAA): Actas de la Comisión Provincial de Monumentos, años 1904 a 1932. Caja 83730-2. 


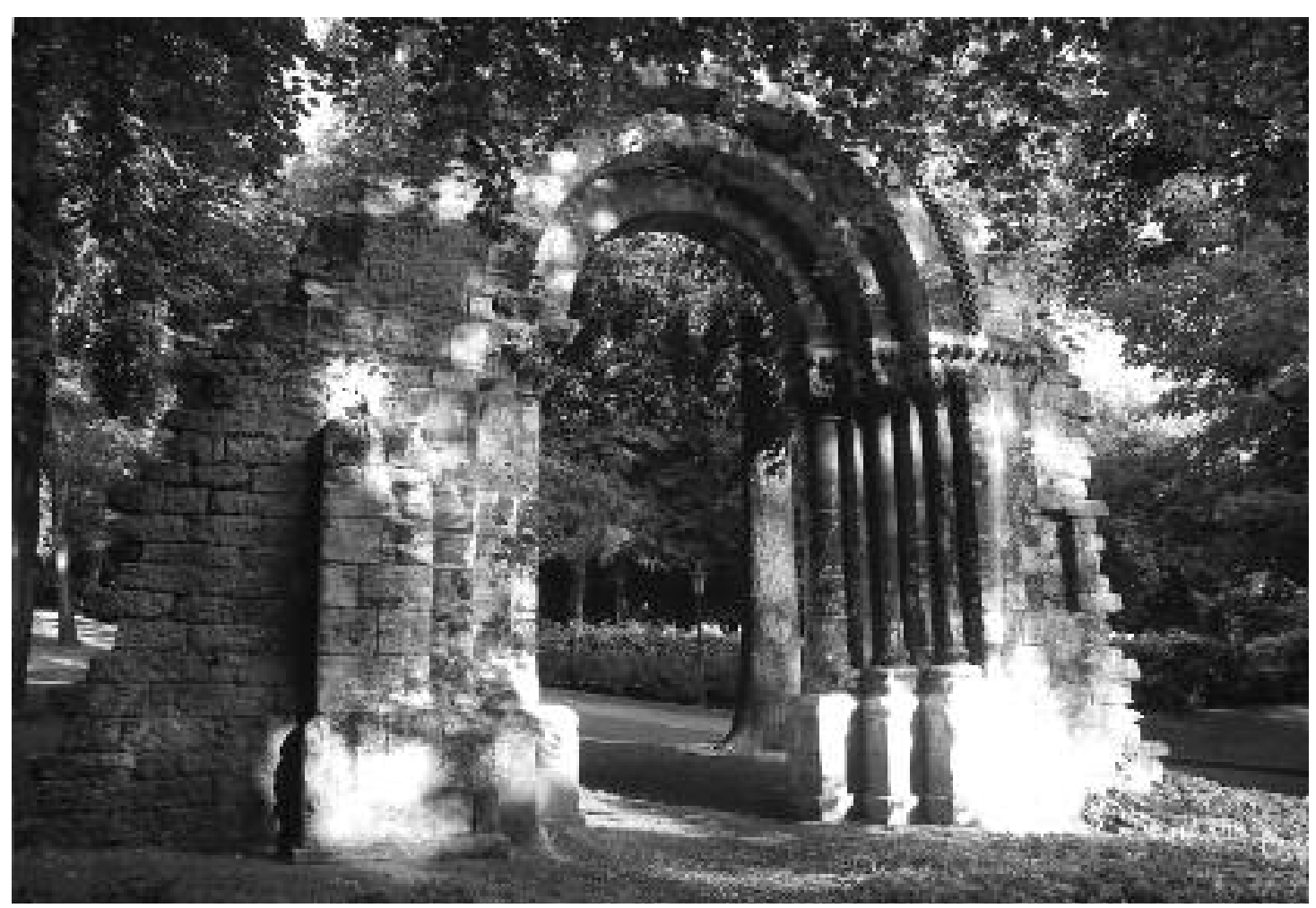

Fig. 5. Arco de la Iglesia de San Isidoro en el Campo de San Francisco de Oviedo. 2015. Fotografía de la autora.

por parte de Hevia, de un adelanto de 6.000 pesetas que es aprobado por la Comisión Permanente, tras los informes favorables del arquitecto municipal y la Comisión de Paseos y Arbolados.

La Comisión Permanente de 4 de marzo de 1926, aprueba el pago a Hevia del saldo final de las obras, 3.620 pesetas, que le son abonadas por libramiento expedido el 12 de marzo de ese mismo año, por lo que suponemos que, en dicha fecha, el arco ya estaba perfectamente instalado en su actual emplazamiento (fig. 5).

En el solar donde estuvo la iglesia de San Isidoro, el Ingeniero municipal Ildefonso Sánchez del Río y Pisón construyó, en 1929, un paraguas de hormigón armado "para tapar a las lecheras» que vendían sus productos en dicho lugar ${ }^{45}$. Por la forma de ese tendejón, el solar pasa a conocerse como la "Plaza del Paraguas», sin que exista constancia de acuerdo oficial del Ayuntamiento adjudicando dicho nombre.

Las posteriores vicisitudes sufridas por el arco de San Isidoro en el Campo, como la desafortunada colocación en 1949 de la estatua de San Francisco de Asís, esculpida por Enrique del Fresno, y su posterior retirada, consideramos que ya no son objeto de este estudio.

45 RAMÓn AlvargonZÁlez RodRíguEZ, «Dos obras del ingeniero Sánchez del Río en Oviedo: El cuarto depósito de aguas y la plaza del Paraguas», en Ástura, 3, Oviedo, 1985, pp. 90-94. 
